\title{
Effects of Angiotensin-Converting Enzyme Inhibitors and Angiotensin Receptor Blockers on Prothrombotic Processes and Myocardial Infarction Risk
}

\author{
Csaba András Dézsi ${ }^{1} \cdot$ Veronika Szentes $^{1}$
}

Published online: 31 August 2016

(C) The Author(s) 2016. This article is published with open access at Springerlink.com

\begin{abstract}
Acute ischemic events occur most frequently at dawn and in the early hours of the morning. The development of these severe clinical events exhibits a temporal relationship with changes in various hemodynamic, prothrombotic, and hormonal processes. The authors highlight not only these relationships but also the potential protective effect of increased bradykinin levels and the inhibition of different angiotensin II (AT-II) receptors (AT2, AT4) against unfavorable prothrombotic influences, whichbased on studies to date-decreases the risk of acute cardiovascular events. Comparisons are presented between the different effects of angiotensin-converting enzyme inhibitors and angiotensin receptor blockers on factors that influence thrombus formation and myocardial infarction risk.
\end{abstract}

\section{Key Points}

The majority of coronary events generally occur at dawn and in the early morning, a timing that may also be relevant to their prevention.

The risk of acute myocardial events is significantly influenced by prothrombotic, hormonal, and hemodynamic processes that occur in the human body according to circadian rhythms.

While the blood pressure-lowering effects of angiotensin-converting enzyme inhibitors and angiotensin receptor blockers (ARBs) should be considered, so too should all other differences that may protect against a plaque rupture leading to myocardial infarction.

\section{Introduction}

Ischemic heart disease is one of the most frequent diseases worldwide, and cardiovascular (CV) diseases are among the leading causes of death in developed industrial countries $[1,2]$. Progressive coronary atherosclerosis is the main pathological base of ischemic heart disease, eventually resulting in overt disease. Two main forms of its manifestation are differentiated in clinical practice: stable coronary artery disease (SCAD) and acute coronary syndrome (ACS), which includes unstable angina (UA) pectoris and various forms of myocardial infarction (MI) such as STsegment elevation myocardial infarction (STEMI) and nonST-segment elevation myocardial infarction (NSTEMI) [3]. As we know, most acute coronary events are underlain
Csaba András Dézsi

dcsa62@gmail.com

1 Department of Cardiology, Petz Aladár County Teaching Hospital, Vasvári Pál str. 2-4, Gyor 9024, Hungary 
by rupture or erosion of plaques, which block the blood supply at given myocardial areas by thrombus formation. In patients who have experienced an acute MI (AMI), the incidence of plaque rupture $(70-75 \%)$ is higher than that of plaque erosion (20-25\%) [3, 4]. The mechanisms leading to unstable plaques are complex, and several local and systemic factors play a part [5]. However, the majority of coronary events occur at dawn and in the early hours of the morning, which may also be of considerable relevance in terms of prevention [6]. The development of acute MI [7] and the closely related mortality shows a significant peak primarily in the period between 6 a.m. and 8 a.m. [8]; the risk of developing events then decreases to the early afternoon (Fig. 1).

\section{Importance of Dawn and the Early Morning Hours and Roles of the Acute Risk Factors}

Although the development of unstable atherosclerotic lesions is regarded as a key step in the initiation of ACS, the mechanism leading to it is only partly understood, but can be concretized with difficulty by highlighting some of its major elements [5, 9]. Plaque instability is determined mainly by a complex of inflammatory processes and immune system activation in the plaque, as well as thrombogenic factors in the circulating blood [10]. In the presence of a vulnerable plaque, the prothrombotic processes that lead to the rupture of the plaque may be triggered by stressors of a physical (e.g., excessive exercise), mental (e.g., workplace stress, anxiety, anger), or chemical (e.g., alcohol, narcotic) nature [11]. However, these risks

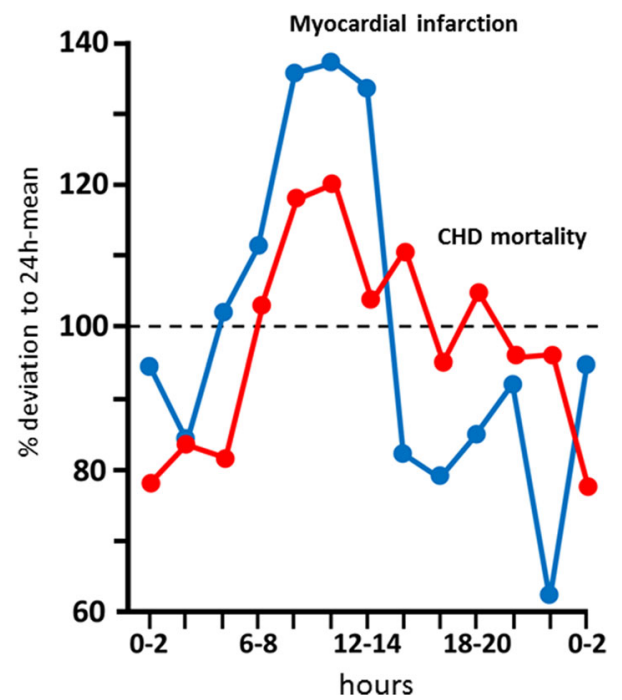

Fig. 1 Circadian rhythm of coronary heart disease mortality and acute myocardial infarction that shows a significant peak primarily in the period between 6 a.m. and 8 a.m. [6-8]. $C H D$ coronary heart disease are characteristic of the active morning and even afternoon parts of the day and do not explain why acute conditions peak with dawn and in the early hours of the morning.

Nevertheless, the development of ACS may be significantly determined by transient biological/physiological changes that follow a circadian rhythm and predominate in the early morning [12]. In addition to the increased sympathetic tonus, the prothrombotic response may be augmented by the dawn increase in blood pressure, platelet activation, and coagulability, and disrupted fibrinolysis balance. These changes acting on the short term are the 'acute risk factors' that represent the final impetus in the process leading to plaque instability and rupture, and may thereby increase the risk of CV events developing [13].

The early morning increase in blood pressure and heart rate enhance myocardial oxygen demand while coronary flow is decreased [14]. The number and activity of circulating platelets may also fluctuate according to circadian rhythms, where catecholamines may also play a role $[15,16]$. The activation of coagulation factors (e.g., Factor VII, fibrinogen, prothrombin), and the decreased morning activity of fibrinolytic system elements (plasminogen activator inhibitor-1 [PAI-1] and tissue plasminogen activator [t-PA]) also follow a circadian rhythm [15-18] (Fig. 2). The differences between the two main processes of cardiac oxygen demand/supply and coagulation/fibrinolytic systems may underlie the development of morning ACS [17, 18]. Results of intravascular ultrasonography (IVUS) angiographies performed prior to coronary interventions demonstrate that the circadian rhythm of AMI can be attributed mostly to the increase in the incidence of plaque ruptures in the morning [19].

Thus, the interactions between primary triggers and acute risk factors (Fig. 3) represent a critical period for acute CV events [13]. Acute risk factors that follow a circadian pattern can be classified into four main groups: hemodynamic effects, prothrombotic conditions, inflammatory reactions, and neurohormonal influences. The effects of apparently unimportant changes such as these may be superposed to disorders already caused by chronic risk factors (e.g., the presence of unstable atherosclerotic plaques due to dyslipidemia and hypertension) and may initiate/enhance the triggered processes that lead to the acute events.

\section{Relationship Between Hypertension and the Prothrombotic State}

Elevated systolic blood pressure $(>140 \mathrm{mmHg})$ is one of the most important risk factors of coronary heart disease (CHD) [20]. Blood pressure also follows a characteristic circadian pattern in healthy people. In hypertensive 
Fig. 2 Circadian rhythm of elements of the fibrinolytic system (plasminogen activator inhibitor [PAI]-1, tissue plasminogen activator [t-PA]) that represents a critical period for acute cardiovascular events [15-18]

Fig. 3 Potential conjunction of triggers (workload, stress, sadness/anger) and acute risk factors (hemodynamic effects, prothrombotic conditions, inflammatory reactions, and neurohormonal influences) that were 'superposed' to disorders already caused by the chronic risk factors and initiate the acute coronary events [13]. BP blood pressure, $C N S$ central nervous system, $H R$ heart rate, $P A I-1$ plasminogen activator inhibitor-1
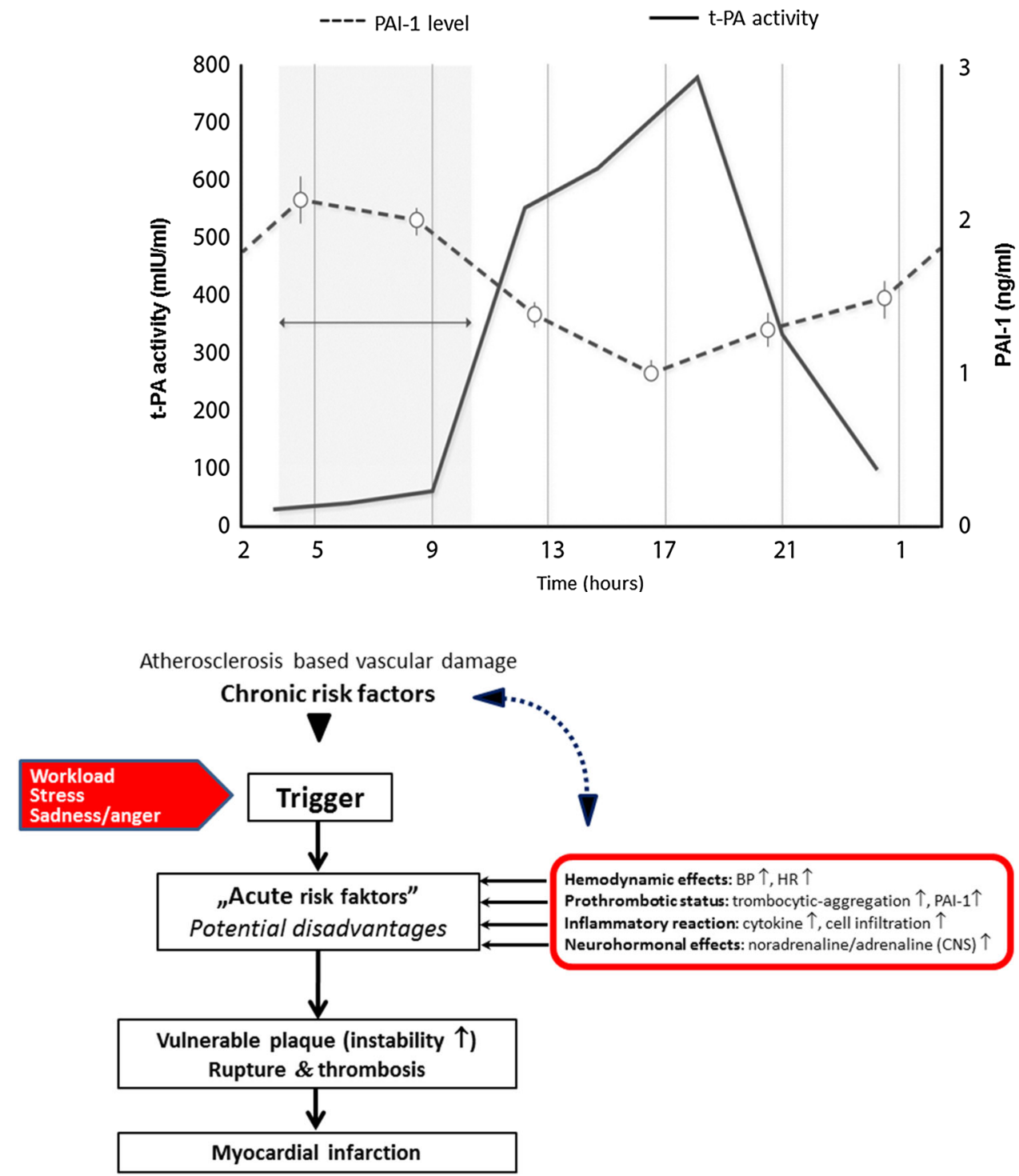

patients, a 24-h blood pressure profile shows changes that result in an increased variability and a morning rise in blood pressure [14, 18]. Raised dawn and early morning blood pressure is one of the most significant acute risk factors that places a greater hemodynamic burden on the coronary circulation and is associated with the activation of several neurohumoral systems [13]. The morning surge in blood pressure represents the greatest danger, primarily for 'non-dipper' or 'extreme dipper' patients; in the former this is due to the pressure load that begins relatively early, at dawn, and lasts for 8-10 h, the latter because of the dangerously steep increase in blood pressure [21]. The flowmediated vasodilatation (FMD) that reflects the functional state of the vessels shows no fluctuation in a healthy population, whereas it fluctuates together with ischemic episodes and is worse in the early morning period in patients with CHD and angina. This may be related to risk factors that follow circadian rhythms [22].

The shearing force on the vascular wall due to hypertension, turbulent flow, developing endothelial dysfunction, atherosclerotic vessel damage, vascular inflammation, and imbalance between hemostasis elements represents a significant prothrombotic and CV risk [16]. For instance, the level of PAI-1 that inhibits the initiation of fibrinolysis is highest in the early morning hours, which can be correlated with the critical period for coronary events [7, 22]. On the other hand, the levels of t-PA responsible for the initiation of fibrinolytic processes are also lowest in the critical dawn period and highest when the risk of developing CV events is the lowest [13, 17, 18, 23]. Platelet aggregability also shows diurnal changes and is at its highest in the early morning hours [24]. 


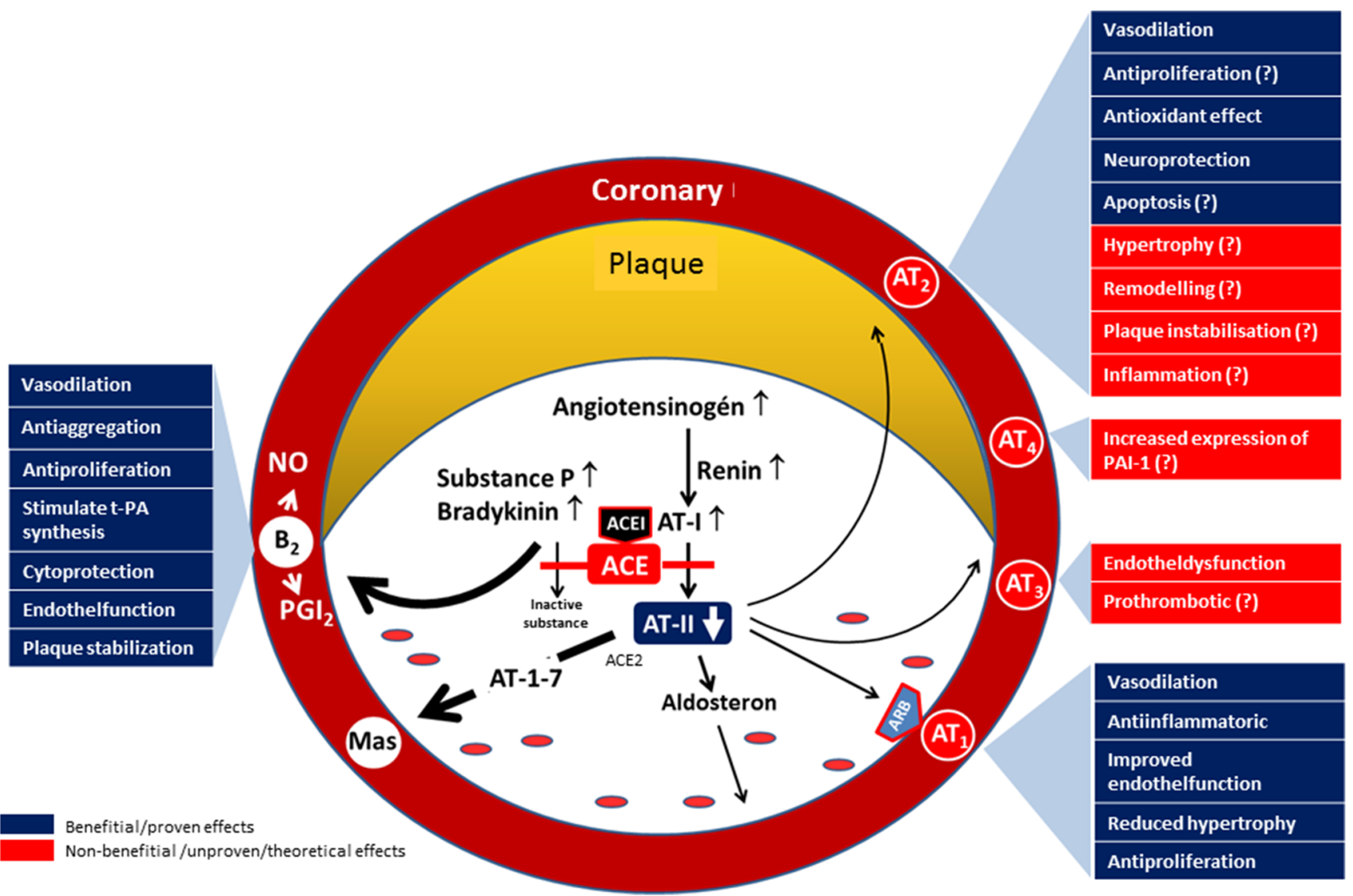

Fig. 4 Presumed differences in mechanisms of action of angiotensinconverting enzyme inhibitors and angiotensin receptor blockers. The elevated levels of plasminogen activator inhibitor-1 and decreased tissue plasminogen activator activity affects coronary circulation, causing coronary heart disease. Evidence suggests that bradykinin (that increased by angiotensin-converting enzyme inhibitors only) stimulates tissue plasminogen activator synthesis and AT4 receptors (that is inhibited by angiotensin-converting enzyme inhibitors only also) results in increased expression of plasminogen activator inhibitor-1 secretion in endothelial cells. This mode of action of angiotensin-converting enzyme inhibitors explains their ability to reduce acute coronary events [25-27]. $A C E(I)$ angiotensin-converting enzyme (inhibitor), $A T$ angiotensin, $N O$ nitric oxide, $P A I-1$ plasminogen activator inhibitor-1, $P G I_{2}$, prostaglandin $\mathrm{I}_{2}, t-P A$ tissue plasminogen activator
Fig. 5 Different effects of the angiotensin-converting enzyme inhibitor perindopril and the angiotensin receptor blocker losartan on factors influencing thrombus formation [37-39]. NS not significant, PAI-1 plasminogen activator inhibitor1, $t$-PA tissue plasminogen activator

\section{PAI-1 level}

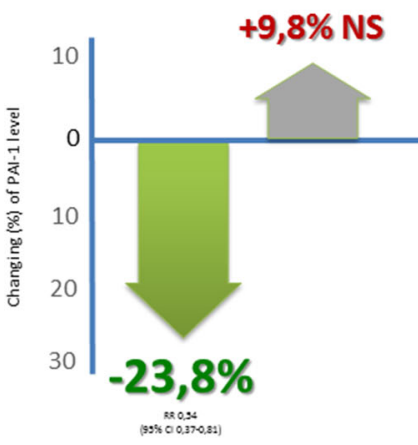

Fibrinogen level

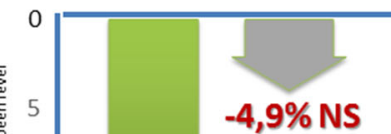

perindopril

losartan 
Summing up, one may state that the well-known circadian rhythm of prothrombotic and other 'acute risk factors' may initiate processes, upon the effects of triggers, which together may increase the chance for plaque rupture in patients with a high CV risk. Renin-angiotensin system (RAAS) inhibitors, which —in addition to their antihypertensive effect—can also reduce plaque instability due to acute risk factors, may reduce the chance of atherosclerosis-based $\mathrm{CV}$ events and the risk of developing an AMI to a greater extent.

Table 1 Differences between mechanisms of action of angiotensinconverting enzyme inhibitors and angiotensin receptor blockers in relation to endothelial function and thrombosis risk [41]

\begin{tabular}{lcc}
\hline & ACEI & ARB \\
\hline Reduces endothelial dysfunction & + & + \\
Reduces inflammation & + & - \\
Reduces cell adhesion & + & + \\
Antithrombotic effect & + & \pm \\
Anti-atherosclerotic effect & + & + \\
Reduces cell apoptosis & + & - \\
Strengthens fibrinolitic balance & + & \pm \\
\hline
\end{tabular}

$A C E I$ angiotensin-converting enzyme inhibitor, $A R B$ angiotensin receptor blocker

\section{Differences Between Angiotensin-Converting Enzyme Inhibitors and Angiotensin Receptor Blockers}

ACEIs and ARBs are the two most often used groups of RAAS inhibitors. The putative difference between the two groups may be related to their differing mechanisms of action. The dissimilarity of therapeutic usefulness may be due partly to the beneficial effects associated with increased bradykinin levels (with ACEIs) and the effects on other angiotensin (AT)-II receptors (AT2, AT4) exerted as subsequent activities by the increasing AT-II levels (with ARBs) [25-27] (Fig. 4).

Several studies in ACEIs have demonstrated that they reduce endothelial dysfunction, inflammatory reactions, cell adhesion, and cell apoptosis [28-30]. In addition to their antithrombotic and antiatherosclerotic effects, they also play a role in the restoration of fibrinolytic balance, exerted in part via the bradykinin-dependent (nitric oxide [NO]) processes, which can be considered a particular property of ACEIs [28, 31-33]. These mechanisms alone apparently explain the greater efficacy of ACEIs with high tissue affinity (e.g., perindopril, ramipril) in the reduction of AMI risk [29, 34, 35].

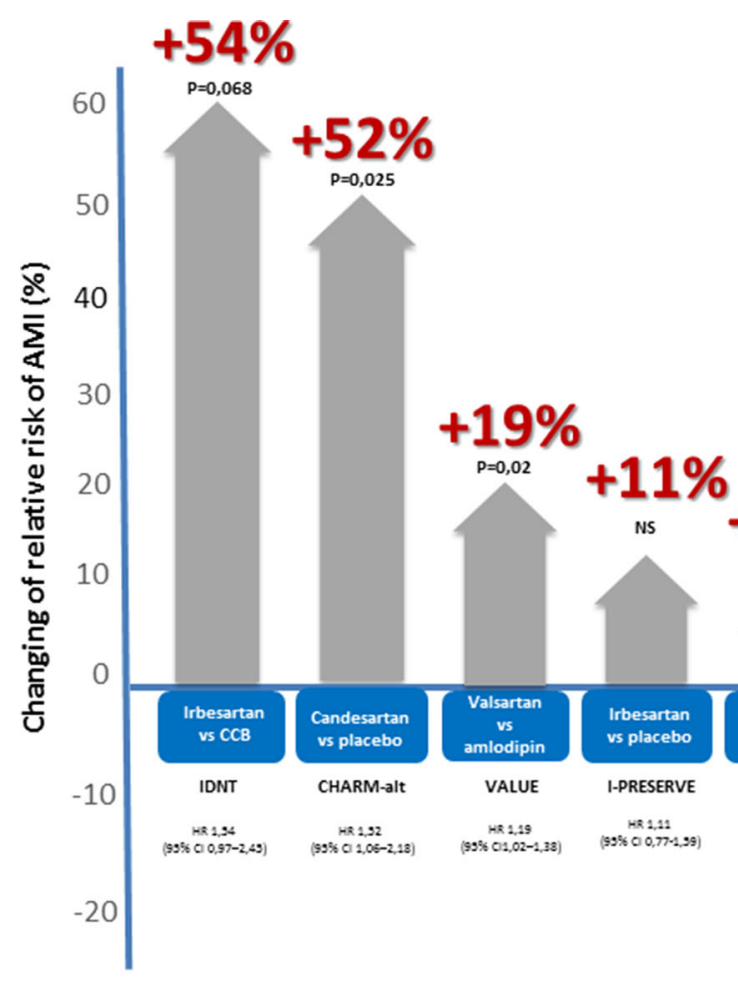

Fig. 6 Different effects of angiotensin-converting enzyme inhibitors and angiotensin receptor blockers on the risk of myocardial infarction compared with placebo or active compounds in some clinical trials

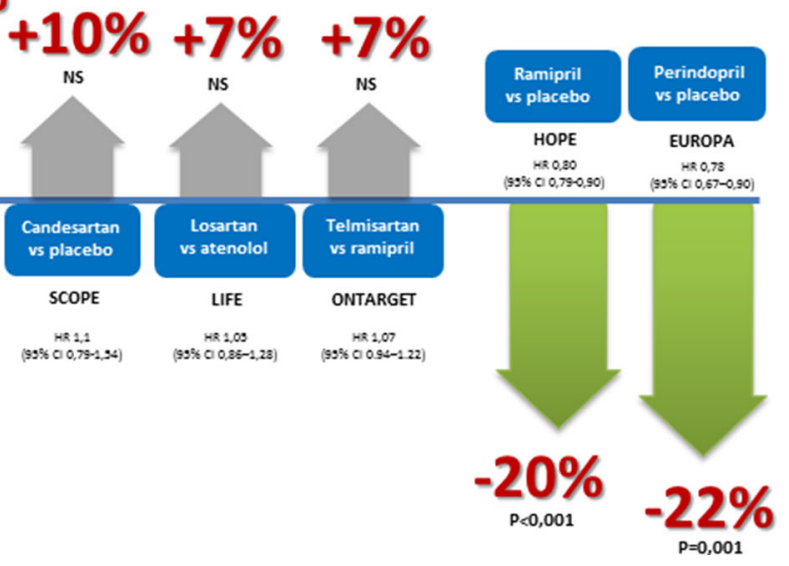

[39-47]. $A M I$ acute myocardial infarction, $C C B$ calcium channel blocker, $C I$ confidence interval, $H R$ hazard ratio 
The binding of ARB to the AT1 type of AT-II receptors causes a compensatory increase of AT-II levels. The free AT-II may bind to other AT-II receptors (AT2, AT3, AT4), which mediate effects resulting in instability and rupture of the plaques [25, 36]. If we compare the effects of perindopril (an ACEI with high tissue affinity), losartan, and telmisartan (ARBs) on the coagulative/prothrombotic factors (PAI-1, plasma fibrinogen, t-PA), we can see significant differences [37-40]. Perindopril exerts more favorable effects than losartan on several parameters (Fig. 5).

Ferrari and colleagues $[26,41]$ compared the mechanisms of action of the two groups of RAAS and their effects on endothelial and vascular functions in detail. They found several differences between the two groups in terms of factors that play a role in functional and structural changes of the vessels. While ACEIs have practical beneficial effects on all parameters, ARBs have only partially beneficial effects in relation to, for example, antithrombotic activity or inflammatory parameters (Table 1).

The surprising effects observed in some clinical studies can be explained by the different effects on prothrombotic factors. The risk of AMI was found to increase with the use of ARBs. This was significant in some cases, in others it was simply a trend compared with control therapies (Fig. 6) [42-49].

The results of ONTARGET also suggest ACEIs and ARBs have different effects and mechanisms of action: the risk of AMI showed a tendency to be lower in the ACEI ramipril group (relative risk [RR] 1.07; $95 \%$ confidence interval [CI] 0.94-1.22); although the mean systolic 24-h blood pressure was significantly (3\%) lower in the ARB group, which can be regarded as clinically significant $[50,51]$.

\section{Conclusion}

Several studies have confirmed that ACEIs effectively reduce blood pressure, including in the critical night/morning period. In addition, they effectively reduce the effects of prothrombotic factors, which follow a circadian rhythm, possibly determined by bradykinin-dependent (NO) mechanisms that can be regarded as specific to this group. In this context, the beneficial effects of ACEIs that reduce the risk of AMI have been demonstrated in several large studies.

Thus, not surprisingly, based on the results of studies with ACEIs and ARBs, both European (European Society of Cardiology [ESC]) and American (American College of Cardiology Foundation [ACCF]/American Heart Association [AHA]) guidelines prefer ACEIs for the prevention of recurring coronary events in patients after an AMI $[52,53]$.
The use of ARBs is only indicated when ACEIs are contraindicated for any reason.

\section{Compliance with Ethical Standards}

The authors take responsibility for all aspects of the reliability and freedom from bias of the data presented and their discussed interpretation.

Funding No external funding was used in the preparation of this manuscript.

Conflicts of interest Csaba András Dézsi and Veronika Szentes have no conflicts of interest that might be relevant to the contents of this manuscript.

Open Access This article is distributed under the terms of the Creative Commons Attribution-NonCommercial 4.0 International License (http://creativecommons.org/licenses/by-nc/4.0/), which permits any noncommercial use, distribution, and reproduction in any medium, provided you give appropriate credit to the original author(s) and the source, provide a link to the Creative Commons license, and indicate if changes were made.

\section{References}

1. Organisation for Economic Co-operation and Development. Health at a Glance 2015: OECD Indicators. Paris: OECD Publishing; 2015. doi:10.1787/health_glance-2015-en.

2. Mozaffarian D, Benjamin EJ, Go AS, et al. Heart disease and stroke statistics-2016 update a report from the American Heart Association. A report from the American Heart Association. AHA Statistical Update. Circulation. 2015;133:e38-360.

3. Willerson JT, Holmes DR Jr (eds) Coronary Heart Disease Syndromes: pathophysiology and clinical recognition. In: Coronary artery disease. London: Springer; 2015. p. 365-407.

4. Virmani R, Kolodgie FD, Burke AP, et al. Lessons from sudden coronary death: a comprehensive morphological classification scheme for atherosclerotic lesions. Arterioscler Thromb Vasc Biol. 2000;20(5): 1262-75.

5. Cimmino G, Conte S, Morello A, et al. The complex puzzle underlying the pathophysiology of acute coronary syndromes: from molecular basis to clinical manifestations. Expert Rev Cardiovasc Ther. 2012;10(12):1533-43.

6. Lemmer B. The importance of circadian rhythms on drug response in hypertension and coronary heart disease-from mice and man. Pharmacol Ther. 2006;111(3):629-51.

7. Muller JE, Stone PH, Turi ZG, et al. Circadian variation in the frequency of onset of acute myocardial infarction. N Engl J Med. 1985;313:1315-22.

8. Mittler MM, Hajdukovic RM, Shafor R, et al. When people die. Cause of death versus time of death. Am J Med. 1987;82:266-74 (PMID: 3812519).

9. Badimon JJ, Ibanez B, Cimmino G. Genesis and dynamics of atherosclerotic lesions: implications for early detection. Cerebrovasc Dis. 2009;27(suppl 1):38-47.

10. Santos-Gallego CG, Picatoste B, Badimón JJ. Pathophysiology of acute coronary syndrome. Curr Atheroscler Rep. 2014;16(401): 1-9 (PMID: 24504549).

11. Mittleman MA, Mostofsky E. Physical, psychological and chemical triggers of acute cardiovascular events preventive strategies. Circulation. 2011;124:346-54. 
12. Bentzon JF, Otsuka F, Virmani R, Falk E. Mechanisms of plaque formation and rupture. Circ. Res. 2014;114:1852-66.

13. Tofler GH, Muller JE. Triggering of acute cardiovascular disease and potential preventive strategies. Circulation. 2006;114:1863-72.

14. Kario K, White WB. Early morning hypertension: what does it contribute to overall cardiovascular risk assessment? J Am Soc Hypertens. 2008;2(6):397-402.

15. Undar L, Türkay C, Korkmaz L. Circadian variation in circulating platelet aggregates. Ann Med. 1989;21(6):429-33.

16. Scheer FA, Shea SA. Human circadian system causes a morning peak in prothrombotic plasminogen activator inhibitor-1 (PAI-1) independent of the sleep/wake cycle. Blood. 2014;123(4):590-3.

17. Feng DL, Tofler GH. Diurnal physiologic processes and circadian variation of acute myocardial infarction. J Cardiovasc Risk. 1995;2(6):494-8.

18. Takeda N, Maemura K. Circadian clock and cardiovascular disease. J Cardiol. 2011;57(3):249-56.

19. Tanaka A, Kawarabayashi T, Fukuda D, et al. Circadian variation of plaque rupture in acute myocardial infarction. Am J Cardiol. 2004;93(1):1-5.

20. Mancia G, Fagard R, Narkiewicz K, et al. ESH/ESC Guidelines for the management of arterial hypertension: The Task Force for the management of arterial hypertension of the European Society of Hypertension (ESH) and of the European Society of Cardiology (ESC). J Hypertens. 2013;31:1281-357.

21. White WB. Clinical assessment of early morning blood pressure in patients with hypertension. Prev Cardiol. 2007;10:210-4.

22. Kawano H, Motoyama T, Yasue H, et al. Endothelial function fluctuates with diurnal variation in the frequency of ischemic episodes in patients with variant angina. J Am Coll Cardiol. 2002;40(2):266-70.

23. Angleton P, Chandler WL, Schmer G. Diurnal variation of tissuetype plasminogen activator and its rapid inhibitor (PAI-1). Circulation. 1989;79:101-6.

24. Tofler GH, Brezinski D, Schafer AI, et al. Concurrent morning increase in platelet aggregability and the risk of myocardial infarction and sudden cardiac death. N Engl J Med. 1987; 316(24):1514-8.

25. Strauss MH, Hall AS. Angiotensin receptor blockers may increase risk of myocardial infarction: unraveling the ARB-MI paradox. Circulation. 2006;114:838-54.

26. Ferrari R, Boersma E. The impact of ACE inhibition on all-cause and cardiovascular mortality in contemporary hypertension trials: a review. Expert Rev Cardiovasc Ther. 2013;11(6):705-17.

27. Dézsi CA. Differences in the clinical effects of angiotensinconverting enzyme inhibitors and angiotensin receptor blockers: a critical review of the evidence. Am J Cardiovasc Drugs. 2014;14(3):167-73.

28. Remková A, Remko M. The role of renin-angiotensin system in prothrombotic state in essential hypertension. Physiol Res. 2010;59:13-23.

29. Ferrari R, Fox K. Insight into the mode of action of ACE inhibition in coronary artery disease the ultimate 'EUROPA' story. Drugs. 2009;69(3):265-77.

30. Ceconi C, Fox KM, Remme WJ, et al. Results of a substudy of the EUROPA study: PERTINENT. Cardiovasc Res. 2007;73: 237-46.

31. Fogari R, Zoppi A. Antihypertensive drugs and fibrinolytic function. Am J Hypertens. 2006;19:1293-9.

32. Erdös EG, Tan F, Skidgel RA. Angiotensin I-converting enzyme inhibitors are allosteric enhancers of kinin B1 and B2 receptor function. Hypertension. 2010;55(2):214-20.

33. Taddei S, Bortolotto L. Unraveling the pivotal role of Bradykinin in ACE inhibitor activity. Am J Cardiovasc Drugs. 2016;16: 309-21.
34. Comini L, Bachetti T, Cargnoni A, et al. Therapeutic modulation of the nitric oxide pathway: are all ACE inhibitors equivalent? Pharmacol Res. 2007;56:42-8.

35. Ruschitzka F, Taddei S. Angiotensin-converting enzyme inhibitors: first-line agents in cardiovascular protection? Eur Heart J. 2012;33:1996-8.

36. Kim MP, Zhou M, Wahl LM. Angiotensin II increases human monocyte matrix metalloproteinase-1 through the AT2 receptor and prostaglandin E2: implications for atherosclerotic plaque rupture. J Leukoc Biol. 2005;78:195-201.

37. Fogari R, Mugellini A, Zoppi A, et al. Losartan and perindopril effects on plasma plasminogen activator inhibitor-1 and fibrinogen in hypertensive type 2 diabetic patients. Am J Hypertens. 2002;15(4 pt 1):316-20 (PMID: 24689028).

38. Matsumoto T, Minai K, Horie $\mathrm{H}$, et al. Angiotensin-converting enzyme inhibition but not angiotensin II type 1 receptor antagonism augments coronary release of tissue plasminogen activator in hypertensive patients. J Am Coll Cardiol. 2003;41(8):1373-9.

39. Fogari R, Zoppi A, Lazzari P, et al. ACE inhibition but not angiotensin II antagonism reduces plasma fibrinogen and insulin resistance in overweight hypertensive patients. J Cardiovasc Pharmacol. 1998;32(4):616-20.

40. Remková A, Kratochvílová H, Durina J. Impact of the therapy by renin-angiotensin system targeting antihypertensive agents perindopril versus telmisartan on prothrombotic state in essential hypertension. J Human Hypertens. 2008;22:338-45.

41. Ferrari R. RAAS inhibition and mortality in hypertension. Glob Cardiol Sci Pract. 2013;3:269-78.

42. Lewis EJ, Hunsicker LG, Clarke WR, et al. Renoprotective effect of the angiotensin-receptor antagonist irbesartan in patients with nephropathy due to type 2 diabetes. N Engl J Med. 2001;345(12): 851-60.

43. Granger CB, McMurray JJ, Yusuf S, et al. Effects of candesartan in patients with chronic heart failure and reduced left-ventricular systolic function intolerant to angiotensin-converting-enzyme inhibitors: the CHARM-Alternative trial. Lancet. 2003; 362(9386):772-6.

44. Julius S, Kjeldsen SE, Weber M, et al. Outcomes in hypertensive patients at high cardiovascular risk treated with regimens based on valsartan or amlodipine: the VALUE randomised trial. Lancet. 2004;363(9426):2022-31.

45. Massie BM, Carson PE, McMurray JJ, et al. Irbesartan in patients with heart failure and preserved ejection fraction. N Engl J Med. 2008;359(23):2456-67.

46. Lithell H, Hansson L, Skoog I, et al. The study on cognition and prognosis in the elderly (SCOPE): principal results of a randomized double-blind intervention trial. $\mathrm{J}$ Hypertens. 2003;21(5):875-86.

47. Dahlöf B, Devereux RB, Kjeldsen SE, et al. Cardiovascular morbidity and mortality in the Losartan Intervention For Endpoint reduction in hypertension study (LIFE): a randomised trial against atenolol. Lancet. 2002;359(9311):995-1003.

48. Yusuf S, Sleight P, Pogue J, et al. Effects of an angiotensinconverting-enzyme inhibitor, ramipril, on cardiovascular events in high-risk patients. The Heart Outcomes Prevention Evaluation Study Investigators. N Engl J Med. 2000;342(3):145-53.

49. Fox KM, EURopean trial On reduction of cardiac events with Perindopril in stable coronary Artery disease Investigators. Efficacy of perindopril in reduction of cardiovascular events among patients with stable coronary artery disease: randomised, doubleblind, placebo-controlled, multicentre trial (the EUROPA study). Lancet. 2003;362(9386):782-8.

50. Yusuf S, Teo KK, Pogue J, et al. Telmisartan, ramipril, or both in patients at high risk for vascular events. $\mathrm{N}$ Engl $\mathrm{J}$ Med. 2008;358(15):1547-59. 
51. Mancia G, Parati G, Bilo G, et al. Ambulatory blood pressure values in the Ongoing Telmisartan Alone and in Combination with Ramipril Global Endpoint Trial (ONTARGET). Hypertension. 2012;60(6):1400-6.

52. Task Force on the management of ST-segment elevation acute myocardial infarction of the European Society of Cardiology (ESC), Steg PG, James SK, et al. ESC Guidelines for the management of acute myocardial infarction in patients presenting with ST-segment elevation. Eur Heart J. 2012;33(20):2569-619.

53. O'Gara PT, Kushner FG, Ascheim DD, et al. 2013 ACCF/AHA guideline for the management of ST-elevation myocardial infarction: executive summary: a report of the American College of Cardiology Foundation/American Heart Association Task Force on Practice Guidelines. Circulation. 2013;127(4):529-55. 